\title{
The Effects of Short-Term Calcium Hydroxide Application on the Strength of Dentine
}

\author{
Dr. Ashish Hedgire ${ }^{1 *}$, Dr. Sarvesha Bhondwe, M.D.S ${ }^{2}$, Dr. Vishal Mahajan, M.D.S ${ }^{3}$, Dr. Rajendra Daule, M.D.S ${ }^{4}$, Dr.
} Sharmika Chechare, M.D.S ${ }^{5}$

\author{
${ }^{1}$ Post Graduate Student, Department of Conservative Dentistry and Endodontics, Y.C.M.M. \& R.D.F'S Dental College, Ahmednagar, \\ Maharashtra, India \\ ${ }^{2}$ Head of Department and Professor, Department of Conservative Dentistry and Endodontics, Y.C.M.M. \& R.D.F'S Dental College, \\ Ahmednagar, Maharashtra, India \\ ${ }^{3}$ Professor, Department of Conservative Dentistry and Endodontics, Y.C.M.M. \& R.D.F'S Dental College, Ahmednagar, Maharashtra, \\ India \\ ${ }^{4}$ Associate Professor, Department of Conservative Dentistry and Endodontics, Y.C.M.M. \& R.D.F'S Dental College, Ahmednagar, \\ Maharashtra, India \\ ${ }^{5}$ Senior Lecturer, Department of Conservative Dentistry and Endodontics, RDC, Loni. Maharashtra, India
}

DOI: $\underline{10.36347 / \text { sjds.2022.v09i01.004 }}$

| Received: 09.12.2021 | Accepted: 15.01.2022 | Published: 28.01.2022

*Corresponding author: Dr. Ashish Hedgire

Post Graduate Student, Department of Conservative Dentistry and Endodontics, Y.C.M.M. \& R.D.F'S Dental College, Ahmednagar, Maharashtra, India

\section{Abstract}

\section{Original Research Article}

The purpose of this study was to see how a short-term application of calcium hydroxide affected the dentine strength of adult human permanent teeth. Materials and methods: We selected 15 disease-free permanent mandibular premolars extracted from humans. The root canals were prepared using rotary equipment and divided into three groups at random. In one group, the root canals were filled with a calcium hydroxide paste (RC Cal) and in another group the root canals were filled with a calcium hydroxide paste (NEO Cal). Canals of teeth in the control group were left empty. All teeth were stored in normal saline for 14 days and then coronal third root dentin cylinders were created by removing the crown and apical portions of the teeth. The compressive forces required to shatter the dentin cylinders were measured using an Instron machine (UNIVERSAL TESTING MASCHINE), and the data was analysed using the Anova test. Results: The calcium hydroxide-filled teeth had a considerably lower mean compressive force than the control teeth $(\mathrm{P}<0.005)$. Conclusion: Teeth that had been exposed to calcium hydroxide for 14 days needed less compressive force to shatter root dentin cylinders. Further research is needed to see if impact testing will provide similar results.

Keywords: Short-Term Calcium Hydroxide Strength of Dentine.

Copyright $\left({ }^{\circ} 2022\right.$ The Author(s): This is an open-access article distributed under the terms of the Creative Commons Attribution 4.0 International License (CC BY-NC 4.0) which permits unrestricted use, distribution, and reproduction in any medium for non-commercial use provided the original author and source are credited.

\section{INTRODUCTION}

The most frequent endodontic intracanal dressing material and pulp capping agent is calcium hydroxide [1] due to its high $\mathrm{pH}$ and beneficial benefits including antibacterial and hard tissue stimulation [2]. It is commonly utilised as both short- and long-term intracanal dressings, and in certain root canal sealers contain it [3]. Another important aspect in its extensive usage and therapeutic effectiveness is its broad range antibacterial action $[4,5]$. This action is proportionate to the capacity of the hydroxide ions to diffuse into the dentin after being liberated from the calcium hydroxide complex [5].
The use of calcium hydroxide to fill root canals for the long term is common, especially when treating young, immature damaged teeth or teeth with significant periapical radiolucent regions. Calcium hydroxide can be utilised in these circumstances for time periods, ranging from 2 to 3 months to 2 or 3 years. For young permanent teeth, the lengthier durations are usually employed to induce the establishment of an apical hard tissue barrier before the root canal filling is completed. Apexification is the term for this procedure. Long-term calcium hydroxide therapy, on the other hand, has been documented to weaken dental roots and lead to the fracturing of young teeth $[6,7]$. 
Placement of calcium hydroxide in the root canal system for brief periods of time ranging from 1 to 4 weeks is a standard technique for the treatment of infected adult teeth with apical periodontitis. As a result, it's critical to determine if shorter-term calcium hydroxide usage in adult teeth has any impacts on dentin. As a result, the purpose of this study was to see how short-term calcium hydroxide treatment affected the strength of human permanent dentin against compressive stresses.

\section{MATERIALS AND METHODS}

This study used fifteen extracted adult human mandibular single rooted permanent premolars with no evidence of decay or restorations. A No. 4 round bur and a high-speed hand piece were used to create an endodontic access cavity in each tooth, and the working length was determined by subtracting $0.5 \mathrm{~mm}$ from the length at which the tip of a file could be visible just extending beyond the apical foramen.

The ProTaper (Dentsply) rotary file system was used to mechanically prepare the root canals according to the manufacturer's instructions. The canals were irrigated with normal saline throughout the preparation process. The teeth were subsequently divided into three groups, each with five teeth: a control group, an RC Cal group, and a NEO Cal group. The canals in the control group's teeth were left open and empty. The canals of the teeth in the other groups were dried and then filled with a calcium hydroxide paste by RC Cal and NEO Cal. A Lentulo spiral (Dentsply) was used in a low speed handpiece to lay the paste. To replicate common in vivo endodontic operations, the access canals were sealed with NEO Temp (orikem). A radiograph was obtained to check that the $\mathrm{Ca}(\mathrm{OH}) 2$ paste had completely filled the canals.

All of the participant's teeth were submerged in a standard saline solution at room temperature for 14 days. A stone disc was then used to cut off the crowns of all teeth at the cemento-enamel junction. The stone discs were used to remove the apical parts of the teeth at a level $5 \mathrm{~mm}$ below where the coronal section was created. The end product was a $5 \mathrm{~mm}$ long dentine cylinder with two smooth sides cleaned with smooth sand paper to provide smooth flat ends to avoid interference with the test machine jaws. The dentine cylinders were then kept in normal saline for the duration of the experiment to prevent them from drying out.

The compressive force necessary to fracture each dentine cylinder was then determined using a universal testing machine (Instron Model) with a crosshead speed of $2 \mathrm{~mm} \mathrm{~min}^{-1}$. The samples were put between the jaws of the testing equipment, and forces were applied vertically from the coronal end of the cylinder to the site of application in the root canal until the cylinder cracked.

Data were expressed as the mean \pm SD for each group. The results were analysed with the Anova One factor test. Statistical calculations were performed using spss software (SPSS Inc., Chicago, IL, USA, version 12.0). Differences were considered significant at $\mathrm{P}<0.05$.

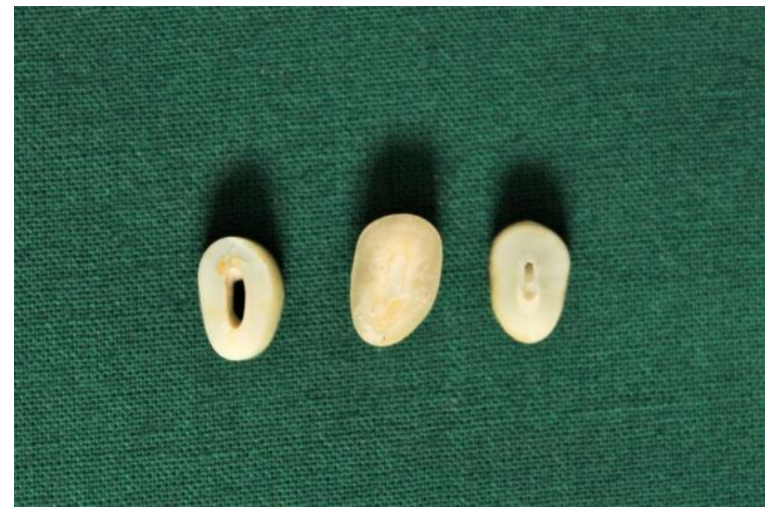

Fig-1: Samples before application of compressive force

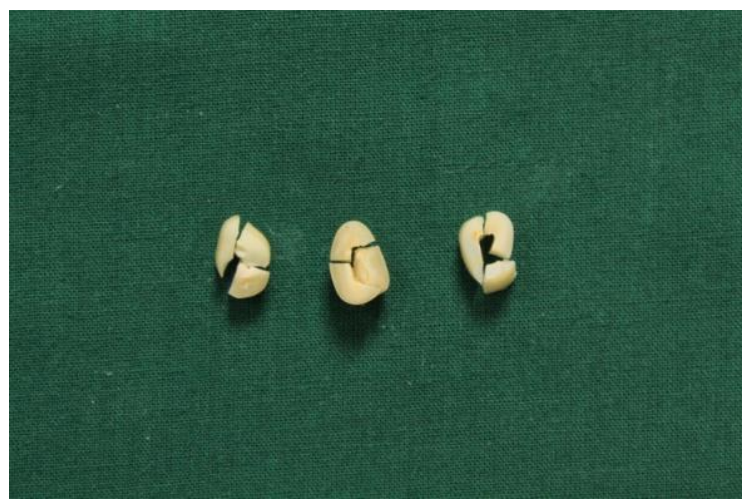

Fig-2: Samples after application of compressive forces

Table -1: The mean and the range of compressive forces required to break the samples.

\begin{tabular}{|l|l|l|l|l|}
\hline Group & No. in group & $\begin{array}{l}\text { Mean compressive force } \\
\text { required } \mathbf{( k g ~ c m - 1 )}\end{array}$ & $\begin{array}{l}\text { Range of compressive force } \\
\text { required } \mathbf{~ k g ~ c m - 1 )}\end{array}$ & SD \\
\hline 1.Control & 5 & 262 & $210-290$ & 31.14482 \\
\hline 2.RC cal & 5 & 174 & $120-220$ & 43.35897 \\
\hline 3. NEO cal & 5 & 164 & $120-210$ & 36.46917 \\
\hline
\end{tabular}




\section{RESULTS}

The results for each group are summarised in Table 1. The mean compressive force required to break the samples in the $\mathrm{RC}$ Cal group and NEO Cal group that were treated with calcium hydroxide was $174 \mathrm{~kg}$ $\mathrm{cm}^{-1}$ and $164 \mathrm{~kg} \mathrm{~cm}{ }^{-1}$ respectively. This was significantly lower than the mean force required in the control group i.e $262 \mathrm{~kg} \mathrm{~cm}^{-1}$. The decrease in dentin strength of $33.5 \%$ in RC Cal group and $37.4 \%$ in NEO $\mathrm{Cal}$ group was statistically significant $(\mathrm{P}$ value is 0.002).

\section{DISCUSSION}

According to the findings of this study, Shortterm root canal filling with calcium hydroxide decreased the strength of dentin in mature human teeth by over $35 \%$ after 14 days. Within 14 days of applying calcium hydroxide, the root strength of the samples was significantly reduced. It should be however, emphasised, that the $35 \%$ decrease in dentin strength was noticed after only 14 days of use.

The interaction of calcium hydroxide with dentin and the changes that occur in the organic matrix that follow first order kinetics may explain the reduction in fracture strength to compressive forces seen after the root canals were filled with calcium hydroxide [8, 9]. The relationship between hydroxyapatite and collagenous fibrils determines dentinal strength, and breakage of this connection occurs due to the high alkalinity of calcium hydroxide. This may cause the carboxylate and phosphate groups to denature, causing the dentin structure to collapse. The acid proteins and proteoglycans that act as bonding agents between the collagen network and the hydroxylapatite crystals in dentin might be neutralised, dissolving, or denaturing, causing the disturbance [10].

When calcium hydroxide is exposed to pulp tissue for just one week, it has a disintegrating impact $[11,12]$. The pulp tissue is denaturated and hydrolyzed to accomplish this. These phenomena might have something to do with the $\mathrm{pH}$ alterations in dentin that occur following calcium hydroxide therapy [13, 14]. Calcium hydroxide might cause severe dentin change if this is the case. This may decrease the biological support of the dentin structure, affecting the mechanical qualities of dentin.

The modulus of elasticity and flexural strength of dentin have been observed to be reduced when root canals are irrigated with sodium hypochlorite [15], this was ascribed to the loss of organic material in dentin [16]. As a result, during the canal preparation phase of the study, only saline was utilised to irrigate the root canals. However, because sodium hypochlorite is routinely used as an irrigant in clinical settings, it's probable that it's contributing to any dentin weakening that happens. More study is needed, and the usage of calcium hydroxide should be reconsidered. Endodontic materials that do not impair the tooth structure, rather than those that damage the dentin, should be employed.

The approach utilised in this study and those published in the literature does not duplicate the normal clinical scenario of pressures being applied to teeth, which is a basic concern. Compressive stresses were applied to a cylinder of dentine obtained from the coronal part of the tooth root in this experiment. The samples lacked any coronal tooth structure, such as enamel, which gives teeth their strength. Only vertical pressures were used, and they were centred within the root canal. The force was given to the dentine cylinder at a consistent pace until it shattered. This sort of force cannot be administered to a tooth in a clinical setting. Instead of a constantly applied force, any force that may cause a tooth root fracture is more likely to be a rapid impact force.

Grigoratos et al. [17] found that dentin specimens treated with calcium hydroxide had a lower flexural strength. This research looked at the forces that were used in a different way. As a result, direct observations with the current situation are impossible, but all of these findings point out that more research is needed. It is necessary to do study and re-evaluate the usage of Calcium hydroxide should be taken into account.

Glen E Doyon et al. [18] done a study that seems to back up the theory that long-term exposure to $\mathrm{Ca}(\mathrm{OH} 2)$ changes dentin's physical characteristics. This might be due to a shift in the organic matrix. $\mathrm{Ca}$ $(\mathrm{OH} 2)$ has been found to disintegrate pulp tissue, a process that might be triggered by denaturation or hydrolysis. Furthermore, the rise in $\mathrm{pH}$, following $\mathrm{Ca}$ $(\mathrm{OH} 2)$ exposure may impair the organic support of the dentin matrix. These processes may disturb the interaction between collagen fibrils and hydroxyapatite crystals, which might have a detrimental impact on dentin's mechanical characteristics.

Furthermore, rather than being vertical, it is more likely to be applied at variable angles to the tooth structure, with the actual angle altering based on the direction of an accidental blow to the teeth or the angle of forces arising from functional and parafunctional habits. The magnitude of the one-time force will be determined by the same criteria. Finally, certain teeth may have coronal tooth structure that makes them more fracture resistant. As a result, the findings of this study may or may not be relevant to clinical conditions.

\section{CONCLUSIONS}

Teeth that had been exposed to calcium hydroxide for 14 days needed less compressive force to fracture root dentin cylinders. It indicates that using calcium hydroxide for a short period of time might markedly impair dentin strength. More research is needed to see if comparable effects would occur if 
additional testing, such as impact testing, were conducted.

\section{REFERENCES}

1. Yoshiba, K., Yoshiba, N., \& Iwaku, M. (1994). Histological observations of hard tissue barrier formation in amputated dental pulp capped with $\alpha$ tricalcium phosphate containing calcium hydroxide. Dental Traumatology, 10(3), 113-120.

2. Zmener, O., Pameijer, C. H., \& Banegas, G. (2007). An in vitro study of the $\mathrm{pH}$ of three calcium hydroxide dressing materials. Dental Traumatology, 23(1), 21-25.

3. Holland, R., \& de Souza, V. (1985). Ability of a new calcium hydroxide root canal filling material to induce hard tissue formation. Journal of Endodontics, 11(12), 535-543.

4. Brännström, M., Vojinovic, O., \& Nordenvall, K. J. (1979). Bacteria and pulpal reactions under silicate cement restorations. The Journal of prosthetic dentistry, 41(3), 290-295.

5. Fisher, F. J., FJ, F., \& JF, M. (1978). Calcium hydroxide base materials. An investigation into the relationship between chemical structure and antibacterial properties.

6. Andreasen, J.O. (1971). Treatment of fractured and avulsed teeth. ASDC J Dent Child, 38; 29-31.

7. Andreasen, F. M., Andreasen, J. O., \& Bayer, T. (1989). Prognosis of root-fractured permanent incisors - prediction of healing modalities. Dental Traumatology, 5(1), 11-22.

8. Sano, H., Shono, T., Sonoda, H., Takatsu, T., Ciucchi, B., Carvalho, R., \& Pashley, D. H. (1994). Relationship between surface area for adhesion and tensile bond strength - evaluation of a microtensile bond test. Dental materials, 10(4), 236-240.
9. Pashley, D. H., Sano, H., Ciucchi, B., Yoshiyama, M., \& Carvalho, R. M. (1995). Adhesion testing of dentin bonding agents: a review. Dental Materials, 11(2), 117-125.

10. Andreasen, J. O., Farik, B., \& Munksgaard, E. C. (2002). Long-term calcium hydroxide as a root canal dressing may increase risk of root fracture. Dental Traumatology, 18(3), 134-137.

11. Andersen, M., Lund, A., Andreasen, J. O., \& Andreasen, F. M. (1992). In vitro solubility of human pulp tissue in calcium hydroxide and sodium hypochlorite. Dental Traumatology, 8(3), 104-108.

12. Hasselgren, G., Olsson, B., \& Cvek, M. (1988). Effects of calcium hydroxide and sodium hypochlorite on the dissolution of necrotic porcine muscle tissue. Journal of endodontics, 14(3), 125127.

13. Nerwich, A., Figdor, D., \& Messer, H. H. (1993). $\mathrm{pH}$ changes in root dentin over a 4 -week period following root canal dressing with calcium hydroxide. Journal of endodontics, 19(6), 302-306.

14. Tronstad, L., Andreasen, J. O., Hasselgren, G., Kristerson, L., \& Riis, I. (1981). pH changes in dental tissues after root canal filling with calcium hydroxide. Journal of endodontics, 7(1), 17-21.

15. Sim, T. P. C., Knowles, J. C., Ng, Y. L., Shelton, J., \& Gulabivala, K. (2001). Effect of sodium hypochlorite on mechanical properties of dentine and tooth surface strain. International endodontic journal, 34(2), 120-132.

16. Driscoll, C. O., Dowker, S. E. P., Anderson, P., Wilson, R. M., \& Gulabivala, K. (2002). Effects of sodium hypochlorite solution on root dentine composition. Journal of Materials Science: Materials in Medicine, 13(2), 219-223. 